\title{
Client Based Capstone Design in Mechanical Engineering at the United States Military Academy
}

\author{
Jerry W. Samples, Mark F. Costello \\ United States Military Academy
}

\begin{abstract}
:
Over the past year the Mechanical Engineering Program at West Point developed a client based capstone design course. The clients for the capstone projects are Army Research, Development, and Engineering Centers, Army Research Laboratories, or other Department of the Army agencies with a need. Since cadet interest in military related projects is high, and finding is relative] y straight forward to secure, this is a win-win program, This paper describes the USMA Mechanical Engineering client based capstone design program as a model of University/Industry partnership. Example projects are described and related to the engineering needs of the Army. Similar experiences can be developed between universities and industries throughout the nation.
\end{abstract}

\section{Background:}

A capstone design experience was a feature of the academic program at West Point many years before ABET accreditation of the Mechanical Engineering Program. In the years before 1984, cadets were required to design and build a device to negotiate a designated obstacle course. The capstone design was loosely translated to mean, get a vehicle that worked and improve on it so that it could win. The competition was excellent because the designs were creative, the participants enthusiastic, and there was always a clear winner. However, the program could not pass the scrutiny of those preparing for the first ABET visit in 1984.

As the Mechanical Engineering program developed to reflect ABET guidance, a capstone design course of considerable analytic difficulty and breadth was needed. The immediate solution was to use the Army to provide design topics that stimulate the students and had the requisite rigor. A further decision to design large military systems restricted the output to "paper designs" to be reviewed by Army Program Managers. Systems considered included: tanks, advanced bridge layers, and anti-tank guns, with all specifications provided in great detail. Large groups were necessary to attack such a formidable problem; teams often or more were the norm. From the standpoint of using all the analysis tools taught in the program, these project were enormously successful. However, from a design engineering standpoint the projects were less than optimal, since student assessment was difficult.

Aside from the obvious difficulties awarding grades to teams as large as ten, there was no real customer when large systems were designed. The requirements documents were very specific, and while there was creativity, much of the vehicle design resembled the current model in the field. The one true variable was the use of tires instead of track. With little creativity and critical thinking involved, the entire design experience was of questionable value, What we had was a rather large, weakly linked analysis exercise that looked like a design. It became apparent that a new design pedagogy needed to replace the old system and that the basis needed to be real clients with real problems.

\section{Capstone Pedagogy:}

Before we jumped into the client based market, we needed to fully understand what the capstone course should be and to ascertain what the students thought the course should do for their education. In essence we 
designed the course to match the Mechanical Engineering Program Academic goals, to satisfy accreditation criteria, and to motivate our primary customer, the student. The results of the course design were the four objectives, listed below, and explained in the paragraphs that follow.

. Provide students with a relevant and realistic design experience.

. Provide a synergistic environment to utilize much of the engineering science and engineering design previously experienced.

. Simulate the design environment that a young design engineer experiences.

. Emphasize the design process through hands-on projects.

The selection of projects was a concern that stimulated a great deal of conversation among the faculty as we developed the program, How complex? How funded? What deliverables? What methods? Who builds the devices? Many other questions were aired as we proceeded with the course development. The requirements that each project should have and an explanation of the design phases follow:

. Projects must draw on many engineering analysis tools learned in the program.

. The process is not the solution, it is merely a means to an end and projects should be physically based not methodology based.

. The time allotted for each project should be 400-500 person hours.

. Each project should be approached in phases to include:

- Specification development and planning phase

- Conceptual design phase

- Detailed design phase

The specification development and planning phase is the customer part of client based design. Once the customer is identified it is important to determine their requirements. Often the customer is unsure of the real need and will provide a vague set of requirements. Requirements must then be prioritized based on their relative importance. Hopefully this is not iterative, but it may be in the case of an ill-defined problem or requirements set. Next, find a product against which the item being designed can be benchmarked. This competitive benchmarking is important and may nullify the need or amplify it. Finally, translate customer requirements into measurable engineering requirements and set engineering targets, Although this is the customer part of the problem, it is also the part that defines the problem, establishes the first set of boundaries, and if satisfied, provides the customer with the desired result.

The conceptual design phase includes concept generation and evaluation, and is really the most creative portion of the design process. In generating concepts the students use functional decomposition to reduce the system to fictional sub-systems, reducing complexity while retaining function. Concepts are generated from functions to develop new ideas through the process of ideation. Ideation and brainstorming are expansive in nature, leading to many solutions to a single problem, Of course, some of the solutions are far-fetched, but it is important to allow for creativity as a new and novel solution may find it's time. The large number of possible concepts are now measured first for feasibility and then through a go/no-go screening technique to reduce the choices to a few realistic ones. Lastly, a decision matrix is developed to select a concept to be developed. The conceptual design phase must have a time line, a cut-off point or the process can become a time sink.

The detailed design phase takes the concept and makes it happen. The selected concept is refined and detailed drawings are produced. Simultaneous system simulation and production of scaled models allows for testing and iteration of the concept. This part of the design is critical in that the students experience the interplay between design and analysis. The prototype is often the deliverable, however in large well funded projects there may be several prototypes tested based on the simulation and modeling tests. The final prototype is then delivered for customer evaluation,

\section{Course Layout:}

The course is offered to second-term Firsties (seniors). Projects are selected and developed from those proposed by outside clients and for participation in professional society design contests. Projects are expected to 
require 400-500 person hours and are assigned to teams consisting of 3-4 students. The total hours are "good" time when productive design and product development is being accomplished. Since this is a learning environment, there are "wasted' hours as the students wrestle with the process and the necessary synergy with material learned throughout their academic experience. Concurrently, the client must be nurtured and cultivated as most of them are new to this level of interaction with novice engineers. Often, the client-engineer interface is the most difficult part of the course to orchestrate.

On the surface, the course layout is very simple, but beneath the surface is an incredible amount of work to ensure that viable projects are available, that sponsors are lined up, and that sufficient "design" faculty are available. In the fall term the project offering list must be developed and faculty members selected to mentor each project. The faculty mentor should organize the project and perform some background research to ensure that the task can be accomplished and that resources are available. Students are surveyed late in the term to rank order project interests. This requires a project abstract so that the students can make informed decisions. The course coordinator then selects teams based on desire, aptitude, personality tests, and the availability of resources. In some cases, many students want the same project and some will be disappointed due to limited resources,

In the spring term, student teams are briefed by the project sponsor to orient them to the customer need. Students are required to develop a project plan that must include the three phases of design. This term plan is critical to the successful completion of the design as it both focuses and curtails the conceptual phase that can occupy large time blocks. Once the schedule is fixed, the process begins. Since students often stray from the plan, weekly project updates, in the form of memos, are provided to the faculty advisor and the project sponsor. These memos keep the team focused and provide input to the mentors. Mentors use the information to assist the team in decision making, to provide needed information, and to keep the team on track if they begin to stray radically from the proposed direction. Upon completion, the team presents a final report and the deliverables along with a briefing to the customer and the faculty advisor. In some cases, the deliverables are then further processed and prototype fielding occurs.

\section{Clients:}

Client selection is critical to the success of the program. Clients must have reasonable projects and reasonable expectations. They must understand that there is a limit to the time available and that they must have a defined project so that work can begin early in the spring term, Since there is considerable interface between clients and students, clients must be willing to communicate via Email, FAX, and voice. They should be readily available, they must read the memos, and they must have some ownership in the success of the project. In essence, the client is a team member; and only one who really knows the requirements of the project.

Clients must also be willing to fund the project. It is difficult to build a prototype based on the budget of the average engineering department, Some finding is necessary to allow for the critical iteration phase inherent in any real design. Travel may be necessary to view the intended use of the prototype or to acquire information from manufacturing sources. The client should fund this also. So, the client must be a player and should be a true believer in the project.

Finally, clients should be picked based on the interests of the faculty and the students. Projects that cannot find a faculty mentor will not be successful. Projects that have no students will not even get a start. This then becomes the most sensitive issue for the course coordinator; balancing the expectations of the faculty and students with the needs of potential sponsors. The most successful projects have the best balance,

\section{Examples Projects:}

Our experience in 1995 was generally excellent. We did however learn a great deal from the projects that did not progress as far as we thought they should. One of our greatest successes was the design of a new medics rucksack for forward deployed Special Operations Medics. This project had a great client, the faculty advisor was a Special Operations soldier, and the team thought the project was very worthwhile since one of the team members had served in Special Forces. The success of this project was set from the beginning. Other projects 
were less successful for various reasons. One ran afoul of classified information, while another was terribly illdefined. In both cases, the projects were difficult to run and the energy level of the students diminished with time.

In 1996, the projects selected for the capstone have been carefully screened to ensure that success is more likely. A list of the project is shown below. Notice that they cover a myriad of subjects and that they use a wide variety of previously covered material. They also have deliverables of many forms and levels of sophistication.

- One-pole Special Operation Forces stretcher detailed design.

- Society of Automotive Engineers Mini-Baja vehicle.

- Sunraycer '97 vehicle design.

- Universal pallet loading system.

- Parachute disengaging device design.

- Heavy-drop anti-overturning parachute device.

- Sunraycer '97 body fairing design.

- Whirlstand experiment design.

- American Institute of Aeronautics and Astronautics aircraft design contest.

- American Helicopter Society rotorcraft design contest.

- Fluid mechanics laboratory design.

- Padnos design competition.

- Canopy design of the Life Support for Trauma and Transport (LSTAT).

- Base design of the LSTAT.

- Design of the LSTAT cooling pad.

\section{Discussion:}

As previously stated, not all of the projects are successful for a variety of reasons. Our most serious concern is the balance between the use of design and engineering science: form over substance. While design and the design process is absolutely essential to the success of the teams, the format of the process can become more important than the outcome itself. It is extremely important that the synergy of the process include ample amounts of engineering science and the accompanying analysis. We found projects that could be accomplished by anyone familiar with the item to be designedh-edesigned even without any formal engineering education. This might be acceptable in the early design courses where the process if being emphasized, however, in the capstone experience there must be a real measure of rigor. Projects without rigor, or those where form supplants substance, send the wrong message to the student and fail to illustrate the importance of engineering analysis in the design of new products. Enter again the course coordinator as the responsible agent for ensuring that projects are viable and satisfy the course objectives.

With a variety of mentors, there is a possibility that the measure of success, the grades, will also vary. This is extremely difficult to manage, as the difficulty of the projects, availability of resources, client interest, and many human factors enter into the success or failure of the design team. The course coordinator should act as the honest broker to ensure equity in grades and effort. If at all possible, the course coordinator should read each project, sit in on all presentations, and to some extent, remain involved with every project.

When deliverables are a requirement of the "contract" between the design team and the client, the mentors must keep the design team on schedule. As in industry, there is a limit to the amount of time allowed for creativity, and the delivery date is generally firm. Some teams will gravitate toward the creative portion of the design since this is fun and requires less analysis. This type of team will never develop a prototype and will always be behind. On the other hand, some teams ignore the creative portion and drive toward a solution as they would in an analysis problem. In this case, the design will be a closed form solution based on the thoughts of one team member. Both situations decrease the probability of success since a balance between creativity and applied engineering science provides optimal learning value. The mentors' role in the success of the team cannot be overstated. 
Project administration is extremely important for both the design team and the client. Design logs are absolutely necessary to keep track of the development of the product and to record the effort of the team. For the mentor, these logs are useful in the grading process as they contain a synopsis of the project, and since each team member keeps a log, they assist in assigning grades to each member. For the client, these logs may contain information of a legal nature. Likewise, weekly progress reports are submitted to keep the mentor and the client abreast of the team's progress. These formal documents assist in keeping the team on track.

\section{Conclusions:}

We believe that our client based design program is an example of the tie required between universities and industries to provide a complete education for our students while providing industry with design products. Our experience has been excellent, but not without problems. The development of a client based design program is one that requires investment of time and energy to ensure that a viable program results. The rewards of the program include: diffusion of design throughout the faculty, realistic design problems, improved prototype capabilities, and a much improved educational environment for the students.

Student comments and the enthusiasm of our clients have been very positive, reinforcing our willingness to continue the client based design program in the future. The students thoroughly enjoy the experience working on "real" problems. They find them challenging, exciting, frustrating, and at times, very difficult. They have a better appreciation for the importance of the requirements document, and the effect of human indecision at times. The clients are returning for a second year and are excited about this year's projects. The clients have contributed more finds, are actively involved in the development of the requirements documents, and plan to spend more time with the teams. The success of the initial program spawned a great deal of interest throughout our client base. These positive result make the effort extremely worthwhile.

\section{References:}

1. Samples, J. W. and Lamkin, F. M. Jr., “ Growth in Design: A Two-Phase Process,” Innovations in Engineering Design Education, Resource Guide, ASME Design Education Conference, Orlando, Florida, March, 1993.

2. Unman, D. G,, The Mechanical Design Process, McGraw-Hill, Inc., New York, New York, 1992

JERRY W. SAMPLES received his BS in Chemical Engineering from Clarkson College of Technology in 1969, and entered the Army as a Corps of Engineers Officer in 1970. He received his MS and PhD. in Mechanical Engineering from Oklahoma State University in 1979 and '83 respectively. He is a Registered Professional Engineer in Virginia and serves as the head of the mechanical engineering program at West Point.

DR. MARK F. COSTELLO is an Assistant Professor of Mechanical Engineering at the U.S. Military Academy. He teaches courses in Mechanical and Aerospace Engineering Design, and Vibration Engineering. His research interests are in the general area of dynamics and control of mechanical and aerospace engineering systems. Before joining the faculty at West Point in 1993, Dr. Costello held engineering positions at the Georgia Tech Research Institute, Boeing Helicopters, and the Naval Air Test Center. 